\title{
PLANO DE CARREIRAS, CARGOS E SALÁRIOS (PCCS) E MOTIVAÇÃO DOS TRABALHADORES EM SAÚDE: A PERCEPÇÃO DOS FUNCIONÁRIOS DA SECRETARIA MUNICIPAL DE SAÚDE DE MANAUS
}

\section{PLAN OF CAREERS, JOBS AND WAGES (PCCS) AND MOTIVATION OF WORKERS IN HEALTH: THE PERCEPTION OF EMPLOYEES OF SECRETARY OF HEALTH MANAUS}

\section{PLAN DE EMPLEOS, EMPLEOS Y SALARIOS (PCCS) Y MOTIVACIÓN DE LOS TRABAJADORES EN LA SALUD: LA PERCEPCIÓN DE LOS EMPLEADOS DEL SECRETARIO DE SALUD MANAUS}

\author{
Luiz Augusto de Carvalho Francisco Soares \\ Universidade Federal do Amazonas \\ las10@uol.com.br
}

Aristides da Rocha Oliveira Junior Universidade Federal do Amazonas aristides.oliveira.jr@gmail.com

\author{
Afrânio de Amorim Francisco Soares Filho \\ Universidade Federal do Amazonas \\ afranio.soares0@gmail.com \\ Ricardo Jorge da Cunha Costa Nogueira \\ Universidade Federal do Amazonas \\ ricardo.nogueira3001@ hotmail.com
}

\begin{abstract}
RESUMO
A implantação do Plano de Carreira, Cargos e Salários (PCCS) nas diversas esferas do setor público brasileiro constitui fenômeno generalizado. Na medida em que expressa o atendimento a uma reivindicação recorrente dos servidores públicos, em prol da conquista de níveis maiores de segurança e satisfação com o trabalho por estes desempenhado, aumenta o interesse por sua implantação. Com foco específico para o setor de saúde pública, o presente estudo explora a relação entre remuneração percebida e a implantação de um PCCS, com base em estudo de caso realizado junto à Secretaria Municipal de Saúde (SEMSA) de Manaus. Os dados foram coletados com base na aplicação de questionários semi-estruturados, entrevistas e análise documental. Os achados da pesquisa indicam que existe uma forte correlação entre a carreira e os elementos que compõem a remuneração e os resultados apontam que no geral o PCCS precisa ser mais bem absorvido por seu público-alvo. Todos os indicadores macros levaram-nos a índices próximos a insatisfação, ou no máximo, a indiferença. Isto significa que o PCCS, nesta unidade de trabalho da SEMSA, está aquém de sua proposta original.
\end{abstract}

Palavras-Chaves: Plano de Carreira; Cargos e Salários; Satisfação com o Trabalho.

\section{ABSTRACT}

The implementation of the Career Plan, Career and Salary (PCCS) in the various spheres of Brazilian public sector is widespread phenomenon. In that it expresses the response to a recurring claim of civil servants, for the sake of achieving greater levels of security and satisfaction with the work performed by them, increases interest in its implementation. With specific focus for the public health sector, this study explores the relationship between compensation and perceived implementation of a PCCS based on a case study conducted by the Municipal Health (SEMSA) from Manaus. Data were collected based on the application of semi-structured questionnaires, interviews and document analysis. The research findings indicate that there is a strong correlation between the career and the elements of the remuneration and the results show that overall the PCCS needs to be better absorbed by your target audience. All macros indicators lead us to rates close dissatisfaction, or at best, indifference. This means that the PCCS, this unit's work Semsa, falls short of its proposal original.

Key Words: Career Planning, Jobs and Salaries, Satisfaction with Work.

\section{RESUMEN}

La implementación del Plan de Carrera, Carreras y Salarios (PCCS) en los distintos ámbitos de sector público brasileño es un fenómeno generalizado. En que expresa la respuesta a una demanda recurrente de los funcionarios públicos, en aras de lograr mayores niveles de seguridad y la satisfacción con el trabajo realizado 
por ellos, aumenta el interés en su implementación. Con un enfoque específico para el sector de la salud pública, este estudio explora la relación entre la remuneración y la ejecución percibida de un PCCS basado en un estudio de caso realizado por la Salud Municipal (Semsa) de Manaus. Los datos fueron recolectados en base a la aplicación de cuestionarios semi-estructurados, entrevistas y análisis de documentos. Los resultados de la investigación indican que hay una fuerte correlación entre la carrera y los elementos de la remuneración y los resultados muestran que en general la PCCS necesita ser mejor absorbida por el público objetivo. Todas las macros indicadores nos llevan a tasas cercanas insatisfacción, o mejor dicho, la indiferencia. Esto significa que los PCCS, SEMSA trabajo de esta unidad, está a la altura de sus original.ves propuesta Palabras clave: planificación de la carrera, Trabajo y Salarios, la satisfacción con el trabajo.

\section{Introdução}

A adoção de Planos de Carreira, Cargos e Salários (PCCS) nas diversas esferas do setor público brasileiro constitui fenômeno que se generaliza, na medida em que expressa o atendimento a uma reivindicação recorrente dos servidores públicos, em prol da conquista de níveis maiores de segurança e satisfação com o trabalho por estes desempenhado. Mas até que ponto os PCCS já implantados têm contribuído para a melhoria efetiva da satisfação dos servidores públicos? Quais os fatores motivacionais mais impactados pela implantação do PCCS, e quais aqueles que pouco influenciam a percepção de satisfação do servidor com o seu trabalho? Com foco específico para o setor de saúde pública, o presente estudo explora a relação entre a remuneração percebida e a implantação de um PCCS, com base em estudo de caso realizado na Secretaria Municipal de Saúde (SEMSA) de Manaus.

Visando esta finalidade, o texto em tela se divide em quatro seções: a primeira, no tópico 02 , recupera alguns focos teóricos que permitem subsidiar a temática de planejamento e gestão de carreiras no setor público, com destaque especial para as organizações vinculadas à saúde pública; a segunda, no tópico 03, constrói uma fundamentação panorâmica sobre a remuneração no serviço público; a terceira, no tópico 04 , apresenta a metodologia utilizada na pesquisa empírica; a quarta, contida no tópico 05, apresenta os resultados da pesquisa realizada junto à SEMSA - unidades distrito Sul; e a quinta, referente ao tópico 06, apresenta algumas conclusões e indicações para pesquisas futuras.

\section{Planejamento e gestão de carreiras na administração pública no Brasil}

O conceito de carreira, enquanto fenômeno vinculado ao mundo do trabalho e das organizações assume diferentes significados: (1) Na visão do senso comum, significa a ascensão vertical na hierarquia de cargos de uma organização, via promoções, ou como a própria profissão/ocupação laboral do indivíduo (ex: carreiras de médico, militares); ou (2) na visão das ciências comportamentais, se configura como a história das ocupações profissionais (e do desempenho de funções e atividades a elas associadas) exercidas pela pessoa ao longo de sua vida. Assim, tanto pode designar a mobilidade ocupacional de um executivo quanto a estabilidade ocupacional da carreira como profissão (MARQUES et al, 2010).

CHANLAT $(1995$; 1996) caracteriza a trajetória da noção de carreira, surgida com a sociedade capitalista industrial no século XIX e sedimentada sobre o ideário do sucesso individual e do progresso sócio-econômico, conforme dois modelos historicamente determinados:

(1) $O$ modelo tradicional, que vigorou em caráter exclusivo até os anos 70 do século passado, e que pressupunha um contexto caracterizado por empregos abundantes e estáveis, reduzida taxa de desemprego e melhoria contínua dos serviços sociais e dos níveis de prosperidade, cujo símbolo maior seria o american way of life. Representado pela metáfora da escada, preconizava a progressão linear e vertical, relativa estabilidade no emprego, enriquecimento de tarefas, divisão sexual e tradicional do trabalho, em que somente os 
homens trabalhavam, e a possibilidade de ascensão pertencia apenas aos grupos socialmente dominantes. Ao se limitar aos avanços verticais e suas marcas de aumento de status e vantagens financeiras, onde a carreira é identificada com as profissões socialmente instituídas e com trabalhos assalariados dentro de organizações, exercidos até a aposentadoria, excluía os trabalhos com status social mais reduzido e os indivíduos com duas ou mais atividades laborais.

(2) $O$ modelo moderno, emergente nos anos 70, contextualizado por fortes mudanças nas instituições sociais: o drástico crescimento do trabalho feminino, incluindo a ascensão da mulher em cargos antes reservados aos homens; a elevação do grau de instrução; e a globalização cultural e econômica, que engendram um modelo de carreiras marcado pela instabilidade, descontinuidade e horizontalidade. Este modelo se destaca nos anos 80, com a profissionalização da gestão nos países industrializados e dos discursos do management, do "capital humano" e da ênfase nas práticas de gestão de RH.

Neste modelo contemporâneo, o planejamento e a gestão das carreiras funcionais tanto se convertem numa tecnologia de gestão, no sentido de técnicas legitimadas pelas teorias e práticas da área de RH (OLIVEIRA Jr., 2002) e pautada no discurso da identificação e valorização das competências técnico-profissionais e pessoais do funcionário, quanto se torna, a partir da mesma matriz discursiva, numa responsabilidade do próprio funcionário, a quem cabe a maior parte do planejamento e da seleção das melhores oportunidades que lhe aparecem durante sua trajetória dentro de uma mesma organização, ou nas várias organizações nas quais venha a trabalhar durante sua vida profissional (MARQUES et al, 2010).

Dentro do modelo moderno, Chanlat (1995) também estrutura uma tipologia de carreiras dividida em burocrática, profissional, empreendedora e sócio-política. A tipologia é mostrada no Quadro 01, a seguir:

\section{Quadro 01 - Tipologia de carreiras e seus elementos caracterizadores}

\begin{tabular}{|c|c|c|c|c|c|}
\hline TIPOS DE CARREIRA & RECURSOS PRINCIPAIS & $\begin{array}{l}\text { ELEMENTO CENTRAL DE } \\
\text { ASCENSÃO }\end{array}$ & TIPOS DE ORGANIZAÇÃO & LIMITES & $\begin{array}{l}\text { TIPOS DE } \\
\text { SOCIEDADE }\end{array}$ \\
\hline BUROCRÁTICA & Posição hierárquica & $\begin{array}{l}\text { Avanço de uma posição } \\
\text { hierárquica a outra }\end{array}$ & $\begin{array}{c}\text { Organizações de grande } \\
\text { porte }\end{array}$ & $\begin{array}{c}\text { O número de escalões } \\
\text { existentes }\end{array}$ & $\begin{array}{l}\text { Sociedade de } \\
\text { empregados }\end{array}$ \\
\hline PROFISSIONAL & Saber e reputação & $\begin{array}{c}\text { Profissão, perícia; } \\
\text { Habilidades profissionais }\end{array}$ & $\begin{array}{l}\text { Organização de peritos; } \\
\text { Burocracia profissional }\end{array}$ & $\begin{array}{l}\text { O nível de perícia e } \\
\text { reparação }\end{array}$ & $\begin{array}{l}\text { Sociedade de } \\
\text { peritos }\end{array}$ \\
\hline EMPREENDEDORA & $\begin{array}{c}\text { Capacidade de criação; } \\
\text { Inovação }\end{array}$ & $\begin{array}{l}\text { Criação de novos valores, } \\
\text { produtos e serviços }\end{array}$ & $\begin{array}{c}\text { Pequenas e médias } \\
\text { empresas; Empresas } \\
\text { artesanais, culturais, } \\
\text { comunitárias e de } \\
\text { caridade }\end{array}$ & $\begin{array}{l}\text { A capacidade pessoal; } \\
\text { As exigências externas }\end{array}$ & $\begin{array}{c}\text { Sociedade que } \\
\text { valoriza a } \\
\text { iniciativa } \\
\text { individual }\end{array}$ \\
\hline SÓCIOPOLÍTICA & $\begin{array}{l}\text { Habilidades sociais; } \\
\text { Capital de relações }\end{array}$ & $\begin{array}{l}\text { Rede social: conhecimento, } \\
\text { relações, parentesco }\end{array}$ & $\begin{array}{c}\text { Familiar; Comunitária } \\
\text { de clãs }\end{array}$ & $\begin{array}{l}\text { O número de relações } \\
\text { conhecidas e ativas }\end{array}$ & $\begin{array}{l}\text { Sociedade de } \\
\text { clãs }\end{array}$ \\
\hline
\end{tabular}

FONTE: Adaptado de Chanlat (1995, p. 72).

Nessa categorização, o burocrático e profissional são os tipos que melhor caracterizam as carreiras no setor público. Isto ocorre pelo fato das organizações públicas estatais na história moderna originarem-se como produtos da sociedade de empregados e de peritos, estes últimos equivalentes ao conceito de tecnoburocratas, que exercem sua perícia técnico-profissional a partir das referências reguladoras do marco legal vigente (OLIVEIRA JR., 2002). No caso do Brasil a transição do foco burocrático para uma ordem estatal 
tecnoburocrática e o efeito gerado sobre a estruturação de carreiras no setor público são perceptíveis.

A estruturação de carreiras no serviço público no Brasil iniciou em 1938, durante o primeiro governo de Getúlio Vargas. Dentre as mudanças geradas pelo, recém implantado, DASP - Departamento Administrativo do Serviço Público destacam-se a consolidação da estabilidade empregatícia nas carreiras estatais e da adoção de instrumentos de planejamento e administração oriundos da área privada. A maioria deste ferramental foi inspirada no modelo burocrático weberiano,. Com a implantação do modelo da administração para o desenvolvimento, nos anos 60, reforçou-se o caráter tecnocrático e centralizador das funções públicas (PIRES e MACÊDO, 2006). Ainda assim, a Constituição Federal de 1969 permitia uma maior mobilidade entre carreiras distintas, ao preconizar que o primeiro ingresso no serviço público fosse pela via do concurso, mas com possibilidade de relocação do funcionário em outras carreiras, através do mecanismo do "provimento derivado" (via concursos internos ou promoção) (AZEVEDO e LOUREIRO, 2003). Com a Constituição Federal de 1988, em seu artigo 37, Inciso II, se estabelece a obrigatoriedade universal do ingresso para quaisquer carreiras do serviço público via concurso, terminando com a anterior mobilidade por provimento derivado.

A crise fiscal que se generalizou sobre grande parte dos países desenvolvidos e em desenvolvimento nas décadas de 70 e 80 (Brasil inclusive, agravado com a crise da dívida externa) motivou um questionamento generalizado do modelo de administração pública burocrática. Reformas são iniciadas em vários países, no sentido da privatização de empresas estatais, do deslocamento do foco em processos ou atividades-meio para resultados para o cidadão, aqui visto como cliente, e da flexibilização das relações de trabalho no setor público, incluindo formas de contratação, remuneração e avaliação de desempenho dos servidores públicos diretamente transpostas das empresas privadas para o setor estatal (OCDE, 1998 e 2001). Todos estes vetores estruturam o paradigma da administração pública "gerencial", que influenciou fortemente o Plano Diretor da Reforma do Estado de 1995. Promulga-se em 1998 a Emenda Constitucional $n^{\circ} 19$, que prevê modificações no regime da administração pública brasileira, para a implementação de institutos mais flexíveis de gestão, mas no que tange à estrutura das carreiras públicas, nenhum avanço substantivo no vetor da flexibilização gerencial é realizado.

O resultado prático dessa trajetória é que, apesar do discurso gerencialista e flexibilizador da gestão de RH no serviço público brasileiro, esta ainda apresenta constrangimentos e limites mais rígidos do que os tradicionalmente encontrados no setor privado, inerentes a este tipo de contexto regulador. No caso brasileiro, alguns exemplos de instituições do direito administrativo são suficientes para caracterizar tal argumento: a) estruturação de carreiras por lei própria, com estipulação de vencimentos pautados no princípio da isonomia e especificação estrita do conteúdo da tarefa, expressa na descrição de cargos e funções; b) recrutamento normalmente realizado pela via do concurso ou seleção pública; c) rigidez nas condições de dispensa do funcionário, que goza de estabilidade contra demissões sem justa causa; d) ausência de mobilidade entre diferentes carreiras etc.

Azevedo e Loureiro (2003) argumentam ser perfeitamente compatíveis a manutenção dos institutos ideais do modelo burocrático de gestão pública (eficiência, profissionalismo, meritocracia no recrutamento do servidor, proteção do conteúdo de cargos e funções contra abusos de autoridade hierárquica etc.) com os imperativos de flexibilidade gerencial, focalizada na busca da eficácia e do aproveitamento criativo das competências funcionais. Neste sentido, a flexibilização da mobilidade de carreiras no serviço público, bem como a implantação de ferramentas mais modernas e rigorosas de avaliação e promoção por desempenho exigem mudanças significativas no marco legal (ex: a flexibilização do princípio da isonomia salarial das carreiras e cargos, a permissão para que funcionários com formação, 
competências e experiência específicas de uma carreira possam ser promovidos para outras carreiras que exijam conhecimentos símiles etc.), mas nada disso rompe necessariamente com o modelo burocrático de gestão. Ao contrário, reforça seus princípios ideais, que são compatíveis, segundo esses autores, com a ordem democrática e com o Estado de Direito de países republicanos.

\section{Satisfação funcional, remuneração e benefícios}

A remuneração do ponto de vista teórico pode ser resumidamente descrita por meio de duas dicotômicas correntes: a tradicional e a estratégica. Ambas pressupõem o estudo do tema através de modelos teóricos e empíricos com diferentes concepções. O modelo tradicional de remuneração baseia-se nos cargos ou tipo de trabalho, por meio de uma visão coletiva, pela qual universaliza os funcionários, enquanto produtores com tarefas similares. Esta padronização ocorre sem considerar como parâmetro remuneratório aspectos individuais como as diferenças de potenciais, expectativas, motivações, objetivos ou desempenho nas organizaçõesFonte bibliográfica inválida especificada..

Os sistemas tradicionais de remuneração normalmente pagam o empregado pelo cargo ou função ocupado, acrescido por valores adicionais decorrentes do tempo de serviço prestado à organização, conhecimento ou competência. Por força legal alguns tipos de organizações são obrigados a oferecer benefícios complementares, neste caso estariam inclusos os planos de previdência privada, convênios médicos-odontológicos, seguros de vida, transporte e clubes de recreação (REIS NETO, 2004)

A abordagem tradicional de remuneração reflete, em última instância, uma forma de pensar o trabalho e a relação com as pessoas, sendo que se encaixa bem em um sistema de gestão burocrático, marcado pela hierarquia e voltado para o controle rígido. Esse sistema foi originalmente desenvolvido para dar suporte à tradicional burocracia característica do período do início da industrialização, enfatizando o controle e encorajando as pessoas a fazerem somente o que estava prescrito, demonstrando que esse sistema depende de certa estabilidade das tarefas desempenhadas para que seja bem sucedido (SILVA Jr, 2001).

Teoricamente, um sistema de remuneração tradicional tende a provisionar a organização de uma ferramenta para administração dos cargos e salários. Não visa interferir ou inter-relacionar a remuneração com outras dimensões da vida organizacional, atuando, somente, como um instrumento neutro. Por este motivo não está associado às dimensões estratégicas, ferindo um dos princípios mais importantes para as modernas empresas: a conversão e alinhamento dos recursos a visão de futuro da organização. Sem este alinhamento, os processos de gestão na organização levam-na a redução de competitividade frente ao cenário globalizado. Levar as pessoas a pensar estrategicamente em prol da organização depende de vários fatores. A remuneração estratégica pode atuar como um elo, responsável pela ligação entre os empregados e a visão estratégica da organização, atuando como um catalisador de esforços. Quando o sistema de remuneração é alinhado ao contexto e à estratégia organizacional, constitui fator de harmonização de interesses e atua como uma alavanca de resultados (WOOD Jr e PICARELLI FILHO, 1999).

Para atender ao dinamismo e flexibilidade exigidos no contexto organizacional, o sistema de remuneração estratégico deve ser aprimorado continuamente, assim como, ser seletivo na incorporação de melhorias. Sua eficácia também depende da percepção de um conjunto de características desejáveis, como: alinhamento aos valores, cultura e metas estratégicas do negócio; vinculação a outras mudanças; integração com outros processos voltados para a gestão de pessoas; democratização no processo de pagamento; clareza na definição das regras; publicidade de suas regras e metodologia de operacionalização a todos 
os funcionários da organização; e vinculação aos resultados quantitativos e qualitativos alcançados (FLANNERY et al, 1997).

A remuneração está ligada a motivação quando se trata de plano de carreiras. Saber o que motiva ou o que satisfaz o trabalhador é poder identificar ações que ao serem desenvolvidas para com ele, podem resultar na melhoria de seu desempenho profissional e, conseqüentemente o desempenho organizacional (SILVA Jr., 2001).

A satisfação e motivação no trabalho têm sido estudadas por diversas correntes teóricas no Séc. XX. Este interesse decorre pela influência que pode exercer sobre o trabalhador, afetando sua saúde, influindo em suas atitudes, comportamento profissional, social, com implicações para a vida pessoal e familiar do indivíduo e das organizações (MARTINEZ e PARAGUAY, 2003).

Para se extrair a satisfação, nesta pesquisa, O sistema remuneratório foi um dos fatores que mais contribuíram para os resultados da presente pesquisa, os quais avaliam a satisfação quanto ao PCCS (Plano de Cargos, Carreiras e Subsídios) na SEMSA (Secretaria Municipal de Saúde) em Manaus.

\section{Metodologia}

A abordagem metodológica é predominantemente quantitativa. A pesquisa caracterizase como um estudo de caso singular (YIN, 2010), pelo objeto de estudo estar restrito às Unidades de Saúde da SEMSA na zona Centro-Sul de Manaus. A Unidade de Análise foi a percepção do impacto do PCCS - Plano de Cargos, Carreiras e Subsídios - aprovado pelo Poder Legislativo Municipal e implantado pela Prefeitura de Manaus em 2008, na satisfação de servidores técnicos e administrativos.

O universo da pesquisa, formado pela totalidade de servidores técnicos e administrativos é de, aproximadamente, 1.750 indivíduos. A técnica de amostragem adotada foi a não-probabilística estratificada por cotas e a seleção da amostra se deu pela conveniência do pesquisador. A amostra foi concentrada somente nos funcionários, não médicos lotados nas unidades da SEMSA distrito Sul na cidade de Manaus.

O tamanho da amostra foi de 177 indivíduos, extrapolando os 161 definidos para um nível de significância de confiabilidade de $95 \%$ e um erro amostral de 5\%, a partir de uma população de tamanho $\mathrm{N}$, com média e desvio-padrão conhecidos, onde $\mathrm{n}=$ tamanho da amostra; $\mathrm{Z}=$ valor da variável $\mathrm{Z}$ para a confiabilidade adotada; $\sigma^{2}=$ variância da população; e = precisão da amostra ou erro máximo admitido e $\mathrm{N}=$ número de elementos da população, conforme a fórmula (1)

$$
n=\frac{N \cdot Z^{2} \cdot \sigma^{2}}{e^{2}(N-1)+Z^{2} \cdot \sigma^{2}}
$$

A técnica de coleta de dados utilizada foi a aplicação de um questionário survey (MALHOTRA, 2006) contendo perguntas fechadas e uma aberta qualitativa para uma amostra. O objetivo do instrumento foi o de relacionar as variáveis dependentes (percepções subjetivas com o PCCS, voltadas para dois eixos principais: a remuneração e a carreira) com a variável independente (implantação do PCCS). O questionário foi desenvolvido com o suporte do Software Spninx ${ }^{\circledR}$, versão 5,1. Os dados, após conferidos foram importados para o programa SPSS ${ }^{\circ}$ (Statistical Package for Social Sciences), versão 20, para análise preliminar dos dados e análise descritiva. Uma pesquisa-piloto ou pré-teste (MALHOTRA, 2006), foi aplicado junto a dez integrantes do setor, conforme recomenda Marconi (2000). O questionário não sofreu modificações após o pré-teste. 
Os dados gerais foram tratados por meio de estatística descritiva (média, desviopadrão) para revelar a intensidade das percepções agregadas sobre as variáveis em tela. A confiabilidade da escala foi medida por meio do Coeficiente Alpha de Cronbach, aceitando como parâmetro de medida índice igual ou superior a 0,60 .

O questionário survey (apêndice) continha uma bateria de avaliação dos impactos do PCCS na motivação do servidor por meio da escala de uma satisfação escala de satisfação, ponderada com pesos diferentes para cada categoria: Muito Satisfeito (5), Satisfeito (4), Indiferente (3), Insatisfeito (2), Muito Insatisfeito (1). As médias obtidas encontram-se no intervalo entre 1 e 5, quanto mais próximo de 5 a média estiver, maior será o nível de satisfação obtido. O instrumento também fez uso de uma pergunta aberta, qualitativa tratada por meio da análise do discurso. Alguns fragmentos do discurso foram utilizados para ilustrar o significado das respostas obtidas. Como métodos complementares ainda foram utilizados a pesquisa documental, de natureza secundária, por meio de consulta a fontes Legais e a entrevistas semi-estruturadas junto a chefia da Unidade Pública Municipal pesquisada.

\section{Estudo de Caso: o PCCS na SEMSA}

O Plano de Carreira da SEMSA - Secretaria Municipal de Saúde, de Manaus (AM) foi instituída pela Lei $\mathrm{n}^{\mathrm{o}} 1.222$, de 26 de março de 2008, em atendimento às diretrizes nacionais para os servidores da área de saúde. Esta lei trata da composição sobre o Plano de Carreiras e Subsídios dos servidores públicos da saúde, seu quantitativo e correspondente subsídio. Tal plano abrange todos os servidores públicos dessa Secretaria com exceção dos servidores Médicos que estão enquadrados em outra legislação (Lei 1.223/2008). Destaca-se que este PCCS previu, também, o enquadramento do servidor público da saúde, que já se encontrava em exercício, na data de entrada em vigência da lei, onde todos os servidores passaram a integrar o serviço dentro de seus parâmetros.

Ao dispor sobre o Plano de Cargos, Carreiras e Subsídios - PCCS, dos servidores públicos as saúde do município de Manaus, esta lei trouxe em seu bojo as seguintes finalidades:

I - fixar padrões e critérios para desenvolvimento nas carreiras que compõem o quadro da Saúde, possibilitando o reconhecimento da Qualificação, do tempo de serviço e do desempenho profissionais;

II - fixar e administrar subsídios em harmonia com os padrões legais, atendidos os critérios de desenvolvimento profissional e as peculiaridades do setor da Saúde e;

III - estabelecer política global para a gestão de pessoas com vistas a promover o desempenho, a motivação, a qualidade, a produtividade e o comprometimento do Servidor Público da Saúde com o resultado de seu trabalho.

Destarte a estas finalidades, fica o questionamento quanto a estas premissas estarem, do ponto de vista do servidor, sendo ou não atingidas. Este é o propósito pelo qual a presente pesquisa busca, junto a esse público, esclarecer. Dessa forma, as questões respondidas mostram tendências colhidas por este pequeno universo, as quais poderão ser generalizadas no futuro, após aplicação da enquete, desta feita junto à amostra representativa do total de funcionários da SEMSA. Os benefícios obtidos na pesquisa permitem a avaliação e construção com base no feedback, de correção de estratégias, melhoria da eficácia do PCCS, para que com ajustes possam vir a estar mais bem aperfeiçoado.

$\mathrm{Na}$ análise do PCCS, alguns destaques, destarte o avanço que este teve na democratização e na definição de qualidades técnicas já definidas, como cursos e titulação a fim de incentivar o servidor, entretanto observa-se que ainda há alguns pontos falhos que podem vir a prejudicar sua eficácia e seu fim específico. Tais pontos são vistos no artigo 27, que trata dos integrantes da Comissão de Avaliação: I - o chefe mediato do Servidor Público 
da Saúde, que a presidirá, competindo-lhe a coordenação dos procedimentos; II - o chefe imediato do Servidor Público da Saúde; e III - um servidor indicado pelo avaliado, ainda traz o preceito de que para cada avaliado será constituída uma comissão. No que tange a tentativa de profissionalização da avaliação periódica do servidor, atendendo a Constituição Federal de 1988, a falha está em não se definir que tipo de servidores (estáveis ou de livre-nomeação) são nomeados como chefes, ou se tem algum limite para a composição dessa comissão. Esta ausência pode vir a construir a situação de servidores técnicos estáveis concursados serem avaliados, na maioria, por servidores não estáveis, de livre-nomeação e políticos, o que pode acarretar a já vista "perseguição" no serviço público, o que, de certo não salutar.

Outro ponto que merece destaque, ainda, e que deve ser ponto de evolução para o aperfeiçoamento do referido PCCS é o fato de não haver pré-requisitos mínimos para que um servidor assumir gerências de departamentos ou de setores. Fica claro, então, que existe a possibilidade de existir, e de fato há, servidor de nível médio gerenciando servidores de nível superior, o que não é nem um pouco estimulante e motivador. Tal ponto traz, também, viés ao fim específico deste Plano de Carreiras, vez que o serviço público de saúde, pode vir a ser gerenciado por servidores com baixo, ou pior qualificação que os outros.

A seguir passa-se a análise dos resultados da pesquisa realizada junto aos servidores da SEMSA quanto à satisfação das regras impostas no PCCS.

\section{Apresentação e análise dos dados}

O questionário utilizou como base catorze variáveis, no processo de avaliação do plano de carreira, são elas: a fixação do salário-base; a fixação ou oportunidade de obtenção de salário variável ou outras remunerações; os benefícios indiretos concedidos no plano de carreira; os níveis de remuneração na carreira; plano de carreira; metas e objetivos; treinamento previsto no plano de carreira; equipamentos a disposição para o desenvolvimento da carreira; ambiente e estrutura de trabalho para o desenvolvimento da carreira; a supervisão e o controle dos acessos aos níveis da carreira; a preocupação da SEMSA com a qualidade de vida do servidor; a sua qualificação para alcançar os níveis da carreira; os prêmios indiretos previstos na carreira; o sistema de reconhecimento das realizações funcionais por parte da SEMSA.

Tabela 1. Avaliação PCCS SEMSA

\begin{tabular}{|c|c|c|c|c|c|}
\hline Categorias & $\mathbf{N}$ & Mínimo & Máximo & Média & $\begin{array}{l}\text { Desvio } \\
\text { Padrão }\end{array}$ \\
\hline A sua qualificação para alcançar os níveis da carreira. & 177 & 1 & 5 & 3,38 & 1,310 \\
\hline Metas e Objetivos. & 177 & 1 & 4 & 3,06 & 1,062 \\
\hline A supervisão e o controle dos acessos aos níveis da carreira. & 158 & 1 & 4 & 3,00 & 1,162 \\
\hline Fixação dos Salários Base. & 177 & 1 & 5 & 2,88 & 1,217 \\
\hline Níveis de remuneração na carreira. & 177 & 1 & 4 & 2,73 & 1,193 \\
\hline Treinamento previsto na carreira. & 161 & 1 & 4 & 2,70 & 1,066 \\
\hline O sistema de reconhecimento das realizações da SEMSA. & 177 & 1 & 4 & 2,56 & 0,903 \\
\hline Plano de carreira de maneira geral. & 177 & 1 & 4 & 2,50 & 1,216 \\
\hline Equipamentos a disposição para desenvolvimento da carreira. & 177 & 1 & 4 & 2,33 & 1,042 \\
\hline Os prêmios indiretos previstos na carreira. & 177 & 1 & 4 & 2,29 & 0,888 \\
\hline Fixação/ oportunidade de Salário variável ou outras remunerações. & 177 & 1 & 4 & 2,28 & 0,891 \\
\hline A preocupação da SEMSA com a qualidade de vida do servidor. & 177 & 1 & 4 & 2,28 & 0,890 \\
\hline Ambiente e estrutura de trabalho para o desenvolvimento da carreira. & 177 & 1 & 4 & 2,25 & 1,009 \\
\hline Os benefícios indiretos concedidos na carreira. & 177 & 1 & 3 & 2,10 & 0,837 \\
\hline Totais & & 1 & 4 & 2,59 & \\
\hline
\end{tabular}

Fonte: dados da pesquisa.

Nota ${ }^{1}$ : Alpha de Cronbach: 0,9499

Nota $^{2}$ : Os parâmetros de avaliação do questionário foram estabelecidos sob a escala de satisfação, tendo sido atribuídos pesos diferentes para cada categoria: Muito Satisfeito (5), Satisfeito (4), Indiferente (3), Insatisfeito (2), Muito Insatisfeito (1). As médias obtidas encontram-se no intervalo entre 1 e 5, quanto mais próximo de 5 a média estiver, maior será o nível de satisfação obtido. 
O coeficiente Alpha obtido $(0,9499)$ indica que os itens formadores da escala possuem elevada confiabilidade e consistência interna. Na Tabela 1 têm-se uma visão geral da pesquisa, onde se pode constatar que a média entre todas as categorias avaliadas foi 2,59 , ou seja, conceitualmente enquadra-se entre os níveis: "insatisfeito" (peso 2) e "indiferente" (peso 3). Os maiores índices de satisfação e motivação dos servidores entrevistados (itens que alcançaram as maiores pontuações) foram "qualificação" $(3,38)$; seguido por "metas e objetivos" (3,06) e "supervisão e controle" $(3,00)$. Estes foram os únicos fatores que alcançaram um intervalo mais próximo do nível 4, "satisfeito. Os itens que menos satisfazem no plano de carreira são "benefícios indiretos", menor entre todas as médias obtidas, 2,10; seguidos por "ambiente e estrutura" com 2,25 e "equipamentos" e "qualidade de vida" ambos com 2,28 .

Os resultados demonstram que os empregados sentem-se qualificados para buscar as projeções no plano de carreira, não consideram as metas e objetivos incoerentes para esta missão, assim como consideram a supervisão e controle impostos pelo PCCS indiferente às suas aspirações. O desvio-padrão, de um modo geral, variou entre 0,837 e 1,310, o que aponta para uma heterogeneidade dos estratos. Esta tendência também pode ser percebida pelos valores mínimos e máximos atribuídos aos fatores avaliados (1 e 4).

Tabela 2- Avaliação PCCS SEMSA, por faixas salariais

\begin{tabular}{lccc}
\hline \multicolumn{1}{c}{ Critérios de avaliação } & Faixas Salariais \\
Acima de $\mathbf{R} 3.000$ & Total \\
Fixação dos Salários Base & De $\mathrm{R} \$ 1.001$ a R $\$ 2999$ & 3,8 & 2,9 \\
Fixação/ oportunidade & 2,0 & 2,8 & 2,3 \\
Benefícios indiretos & 1,8 & 2,0 & 2,1 \\
Níveis de remuneração & 2,2 & 3,4 & 2,7 \\
Plano de carreira & 2,0 & 3,2 & 2,5 \\
Metas e Objetivos & 1,8 & 3,4 & 3,1 \\
Treinamento & 2,8 & 2,8 & 2,7 \\
Equipamentos & 2,5 & 2,6 & 2,3 \\
Ambiente e Estrutura & 2,0 & 2,4 & 2,2 \\
Supervisão e Controle & 2,0 & 3,2 & 3,0 \\
Qualidade de vida & 2,8 & 2,6 & 2,3 \\
Qualificação & 2,0 & 4,0 & 3,4 \\
Prêmios Indiretos & 2,8 & 3,0 & 2,3 \\
Sistema de reconhecimento & 1,6 & 3,2 & 2,6 \\
\hline
\end{tabular}

Fonte: dados da pesquisa.

Na Tabela 2 percebe-se que o PCCS agrada mais os que detêm maiores salários. Em 13 dos 14 itens avaliados os com rendimento acima de R \$3 mil avaliaram melhor o PCCS que o grupo com rendimento inferior, entre $\mathrm{R} \$ 1.001$ e $\mathrm{R} \$ 2.999$. Para este grupo, a insatisfação quanto ao plano de carreira do órgão municipal, se mostra, principalmente, em fatores como "prêmios indiretos" $(1,6)$, "fixação de oportunidades" $(1,8)$ e "plano de carreira" $(1,8)$. Para o grupo com maior satisfação, a visão mostra-se diferente, uma vez que "qualificação" $(4,0)$, "fixação de salários base" $(3,8)$; "níveis de remuneração" $(3,4)$ e "metas e objetivos", são os fatores que mais agradaram no plano de carreira.

Os resultados podem indicar uma visão distorcida do plano pelos que ganham menos. Extraíram-se os comentários sobre o que poderia ser melhorado no PCCS neste grupo e se pôde identificar trechos do discurso dos indivíduos, os quais mencionam questões como isonomia salarial e de funções, além da própria remuneração. Isto pode sinalizar um sentimento de injustiça e discriminação associado a privilégios aos mais bem remunerados.

(Q1)“deveria ser comparado com plano dos servidores públicos federais e principalmente a isonomia nas carreiras de nível médio e superior, tendo proporção."

(Q5) “motivar o servidor do ensino médio a fazer um ensino superior motivação dentro do trabalho para aumentar suas habilidades e dar vontade de trabalhar mais." 
(Q7)"fazer o enquadramento dos servidores novos."

(Q8) "melhorar a remuneração do servidor através do ganho por produtividade."

(Q9) “o reajuste de nível médio deveria ser proporcional ao reajuste de nível superior."

Para melhor caracterizar estes dois grupos distintos, analisam-se os comentários dos com rendimentos acima de $\mathrm{R} \$ 3$ mil, quanto aos fatores que poderiam ser melhorados no PCCS, e logo se percebe que a maioria das questões voltaram-se para a clareza dos critérios de progressão funcional.

(Q 2) "Diminuição dos prazos para avaliação de titulação e progressão por mérito e tempo de serviço."

(Q 3) "Reduzir o prazo para verificar titulação e progressão anual para o tempo de serviço."

(Q 6) "mudança relativa a questão do enquadramento, gerando para os futuros servidores o direito de serem enquadrados com suas especificações quando for o caso, no inicio de sua carreira."

(Q 10) "melhor avaliação dos critérios para mudança nos níveis do plano de carreira no que se refere a pós-graduação. Mudança do tempo mínimo para licença prêmio ao invés de 10 anos e 6 meses, para 5 anos e 3 meses."

Tabela 3. Avaliação PCCS, por área de trabalho

Critérios de avaliação

\section{Fixação dos Salários Base}

Fixação/ oportunidade

Benefícios indiretos

Níveis de remuneração

Plano de carreira

Metas e Objetivos

Treinamento

Equipamentos

Ambiente e Estrutura

Supervisão e Controle

Qualidade de vida

Qualificação

Prêmios Indiretos

Sistema de reconhecimento

Fonte: dados da pesquisa
Área de trabalho na instituição

\begin{tabular}{ccc} 
Outra área (Técnica,...) & Administrativa & TOTAL \\
2,7 & 3,0 & 2,9 \\
2,0 & 2,4 & 2,3 \\
2,0 & 2,1 & 2,1 \\
2,3 & 2,9 & 2,7 \\
1,7 & 2,9 & 2,5 \\
2,7 & 3,3 & 3,1 \\
2,3 & 2,8 & 2,7 \\
1,7 & 2,6 & 2,3 \\
2,0 & 2,3 & 2,2 \\
3,0 & 3,0 & 3,0 \\
2,3 & 2,3 & 2,3 \\
3,0 & 3,6 & 3,4 \\
2,3 & 2,3 & 2,3 \\
2,7 & 2,6 & 2,6 \\
\hline
\end{tabular}

Na tabela 3 os dados formam um conjunto mais equilibrado de resultados. As médias mantiveram-se parelhas entre os funcionários da área administrativa e os de outras áreas. Nas áreas não-administrativas, em especial as técnicas, os índices para "equipamentos" $(1,7)$, "plano de carreira" $(1,7)$, além de "ambiente e estrutura" $(2,0)$; "benefícios indiretos" $(2,0)$ e "fixação de oportunidades" $(2,0)$, foram muito negativamente avaliados, o que demonstra uma tendência a despreocupação quanto às ferramentas e ambiente de trabalho, essenciais ao corpo técnico. Na área administrativa a "qualificação" $(3,6)$ e as "metas e objetivos" $(3,4)$ foram os pontos mais positivos identificados no PCCS.

Tabela 4. Avaliação PCCS, por sexo.

Critérios de avaliação

Fixação dos Salários Base

Homem

3,3

Fixação/ oportunidade

\begin{tabular}{cc} 
Sexo & Total \\
Mulher & 2,9 \\
2,3 & 2,3 \\
1,8 & \\
\hline
\end{tabular}




\begin{tabular}{llcc}
\hline Benefícios indiretos & 2,7 & 1,3 & 2,1 \\
Níveis de remuneração & 3,3 & 1,8 & 2,7 \\
Plano de carreira & 3,2 & 1,5 & 2,5 \\
Metas e Objetivos & 3,3 & 2,8 & 3,1 \\
Treinamento & 3,4 & 1,8 & 2,7 \\
Equipamentos & 2,7 & 1,8 & 2,3 \\
Ambiente e Estrutura & 2,5 & 1,8 & 2,2 \\
Supervisão e Controle & 3,2 & 2,8 & 3,0 \\
Qualidade de vida & 2,5 & 2,0 & 2,3 \\
Qualificação & 3,7 & 3,0 & 3,4 \\
Prêmios Indiretos & 2,5 & 2,0 & 2,3 \\
Sistema de reconhecimento & 2,8 & 2,3 & 2,6 \\
\hline Fonte: Dados da Pesquisa
\end{tabular}

Fonte: Dados da Pesquisa

Entre os gêneros, percebe-se uma relação de desconforto por parte das mulheres, uma vez que metade dos indicadores avaliados no PCCS obteve média inferior a 2,0. Dentre as piores percepções estão os "benefícios indiretos" $(1,3)$ e o "plano de carreira" $(1,5)$, na mesma linha de pensamento, ainda ficaram as "oportunidades fixadas" $(1,8)$, os "níveis de remuneração" $(1,8)$; "treinamento" $(1,8)$; "equipamentos" $(1,8)$ e "estrutura" $(1,8)$.

Para cada 4 mulheres no setor, 3 estão insatisfeitas com o PCCS. Isto pode estar acontecendo por fatores discriminatórios, anteriores a implantação do plano de carreira, mas, certamente a chegada do PCCS não foi visto como solução pelas mulheres do setor.

\section{Conclusões e recomendações finais}

Seria imprudência dos pesquisadores considerarem os resultados como conclusivos, uma vez que se trata de uma pesquisa com levantamento em um único setor na SEMSA. Porém os dados, apesar de serem relativos a um pequeno universo, não se pode negar a sua contribuição ao indicar tendências que poderão vir a ser generalizadas ou testadas em futuras pesquisas.

De acordo com a Lei no 1.222 (2008), através da qual o PCCS foi instituído, define em seu teor os objetivos do plano, os quais podem ser resumidos em três pontos principais: (1) fixação de padrões e critérios para desenvolvimento das carreiras que compõem o quadro da Saúde, possibilitando o reconhecimento da Qualificação, do tempo de serviço e do desempenho profissionais; (2) fixação e administração dos subsídios alcançados pelo atendimento dos critérios de desenvolvimento profissional e as peculiaridades do setor da Saúde; e, por fim (3), o estabelecimento de política global para a gestão de pessoas com vistas a promover o desempenho, a motivação, a qualidade, a produtividade e o comprometimento do Servidor Público da Saúde com o resultado de seu trabalho.

Quanto à fixação de padrões e critérios para o desenvolvimento de carreiras, o PCCS, tomando por base os resultados em 7 dos 14 critérios, voltados para a padronização (fixação dos salários base; fixação de oportunidade; níveis de remuneração; plano de carreira; metas e objetivos; supervisão e controle e qualificação) e a média do estrato $(2,84)$, pode-se indicar uma tendência, pelo intervalo das escalas testadas, entre a insatisfação e a indiferença, com aproximação ao segundo.

No caso da fixação e administração dos subsídios alcançados por meio do atendimento dos critérios de desenvolvimento profissional, presentes em 5 dos 14 critérios analisados (benefícios indiretos; treinamento; prêmios indiretos; sistema de reconhecimento), com média no estrato de 2,41, percebe-se que, neste quesito o PCCS está pior que o anterior. Os índices apontam para o mesmo intervalo, entre a insatisfação e a indiferença, porém com aproximação ao primeiro, insatisfação. 
Na terceira vertente do PCCS, as políticas globais para a gestão do plano de carreira, representadas pelos Equipamentos, Ambiente/Estrutura e Qualidade de vida percebida pelos empregados, a média do estrato foi a menor dentre os avaliados, 2,27. Isto posicionou o indicador entre a insatisfação e a indiferença, porém com a maior aproximação a insatisfação.

Diante do exposto, percebe-se que no geral o PCCS precisa ser mais bem absorvido por seu público-alvo. Todos os indicadores macros levaram-nos a índices próximos a insatisfação, ou no máximo, a indiferença. Isto significa que o PCCS, nesta unidade de trabalho da SEMSA, está aquém de sua proposta original.

Recomenda-se do ponto de vista prático, uma revisão na comunicação para corrigir vieses no entendimento dos critérios e, sobretudo, a revisão dos enlaces entre qualificação, remuneração, produtividade e critérios de desenvolvimento da carreira. Sob a ótica teórica, este resultado aguça a vontade destes pesquisadores em aplicar a mesma pesquisa, desta vez, a uma amostra que represente a totalidade dos funcionários sob a guarda do PCCS na SEMSA.

\section{Referências}

AZEVEDO, C. B.; LOUREIRO, M. R. Carreiras públicas em uma ordem democrática: entre os modelos burocrático e gerencial. Revista do Serviço Público - RSP. Brasília: ENAP, 2003. v. 54, n. 01, jan./mar. 2003, p. 45-60.

CHANLAT, J. F. Quais carreiras e para qual sociedade (I). In: Revista de Administração de Empresas - RAE. São Paulo: EAESP-FGV, 1995. v. 35, n. 06, nov./dez. 1995, p. 67-75.

CHANLAT, J. F. Quais carreiras e para qual sociedade (II). In: Revista de Administração de Empresas - RAE. São Paulo: EAESP-FGV, 1996. v. 36, n. 01, jan./fev./mar. 1996, p. 13-20.

FAVERET, A.C. Padrões de Financiamento e Descentralização na Federação Brasileira: Saúde e Educação Fundamental nos Anos 90. Projeto de Dissertação de Doutorado apresentado ao Programa de Pós-Graduação em Saúde Coletiva. Rio de Janeiro: Instituto de Medicina Social / UERJ, 1999.

FLANNERY, THOMAS P.; HOFRICTER, DAVID A; PLATTEN, PAUL E. Alinhando a remuneração à estratégia de mudanças e à cultura das organizações. RAE Light, 1996. v.3, n.1, p. 22-27,.

KANTER, R. M. O Ataque ao Salário. In: VROON, V. Gestão de Pessoas, Não de Pessoal. Rio de Janeiro: Ed. Campus, 1997.

LAWLER III, E. The Ultimate Advantage: Creating the High Involvement Organization. San Francisco: Jossey-Brass, 1992.

MALHOTRA, N. K. Pesquisa de Marketing. Porto Alegre: Bookman, 2006.

MARQUES, A. L.; NASCIMENTO, J. G. S.; ALBUQUERQUE, A. L. Inovação em Gestão de Pessoas no Setor Público: um estudo sobre a cooperação dos servidores a implantação dos novos planos de carreiras pelo Governo de Minas Gerais. In: Anais do Encontro de Administração Pública e Governança - ENAPG 2010. Vitória: ANPAD, 2010. 
MARTINEZ, M. C.; PARAGUAY, A. I. Satisfação e saúde no trabalho - aspectos conceituais e metodológicos. Cadernos de Psicologia Social do Trabalho, 2003. v. 6, pp. 59-78.

OCDE - Flexibilidade na gestão de pessoal da administração pública. Cadernos ENAP. Brasília: ENAP, 1998. n. 16.

OCDE/PUMA. Desenvolvimentos recentes na gestão dos recursos humanos nos paísesmembros da OCDE. Revista do Serviço Público. Brasília: ENAP, Ano 52, n. 02, abr./jun. 2001, p. 48-66.

OLIVEIRA Jr., A. R. A gestão estratégica no terceiro setor: estudo de caso em uma organização religiosa eclesiástica no Amazonas. Novos Cadernos NAEA. Belém: NAEAUFPA, v. 05, n. 02, dez. 2002, p. 05-87.

PIRES, J. C. S.; MACÊDO, K. B. Cultura organizacional em organizações públicas no Brasil. Revista de Administração Pública - RAP. Rio de Janeiro: EBAPE/FGV, v. 40, n. 01, jan./fev. 2006, p. 81-105.

REIS NETO, M. T. A remuneração variável na percepção dos empregados e suas conseqüências na motivação e no desempenho. Tese de doutorado em Administração. Centro de Pós-Graduação e Pesquisas da Faculdade de Ciências Econômicas, Universidade Federal de Minas Gerais, Belo Horizonte, 2004.

SILVA Jr., N. A. Satisfação no trabalho: um estudo entre os funcionários dos hotéis de João Pessoa. Psico-USF, jan-Jun, 2001. 6, pp. 47-57.

WOOD, Jr. T.; PICARELLI FILHO, V. P. Remuneração Estratégica: a nova vantagem competitiva. $3^{\text {a }}$ ed. São Paulo: Atlas, 1999.

YIN, R. K. Estudo de Caso: planejamento e métodos. 04 ed., Porto Alegre: Bookman, 2010. 
Revista de Administração Hospitalar, v.10, n.1, pp. 61-74, jan/maio, 2013/ Luiz Augusto de Carvalho Francisco Soares; Afrânio de Amorim Francisco Soares Filho; Aristides da Rocha Oliveira Junior; Ricardo Jorge da Cunha Costa Nogueira.

\section{Apêndice: Modelo de Questionário}

\section{SATISFAC̃̃O - PANO DE CARREIRA}

Este questionário é simples, rápido e fácil de preencher. Em 5 minutos você conseguirá fazê-lo e com isto estará colaborando para uma pesquisa do Curso de Doutorado.

Desde já agradecemos suas respostas.

Abril 2011

CONTROLE

1.Data

PEFIU

2.Sexo

- 1 . Homem

2. Mulher

3.Faixa Etária

2. De 21 a 30 anos

3. De 31 a 40 anos

5 . Acima de 51 anos

4.Escolaridade

4.Escolaridade

1. 10. Grau

3. Superior Incompleto

4. Superior Completo

5. Pós Graduação

5.Tempo na empresa

- 1. Até 1 ano

2. Até 2 anos

3. Até 3 anos

5. Mais de 4 anos

6.Renda mensal

2. De R\$601 a R\$1.000

De $R \$ 1.001$ a $R \$ 1.500$

4. De R\$1.501 a $R \$ 2.000$

6. Acima de R\$3.000

7.Área Funciona

- 1. Técnica

2. Administrativa

2. Adminis

AVALIAÇÃO DO PLANO DE CARREIRA

8.Fixação dos Salários base

|- 1. Muito Satisfeito

2. Satisfeito

3. Indiferente
4. Insatisfeito

5. Muito Insatisfeito

9.Fixação/oportunidade de Sálario variável ou outras

remunerações

[_ 1. Muito Satisfeito

2. Satisfeito

3. Indiferente

5. Muito Insatisfeito

10. Os benefícios indiretos concedidos na carreira

- 1. Muito Satisfeito

2. Satisfeito
3. Indiferente

4. Insatisfeito

5. Muito Insatisfeito

11. Os Níveis de remuneração na carreira

1 . Muito Satisfeito

2. Satisfeito
3. Indiferente

4. Insatisfeito

5. Muito Insatisfeito

12.Plano de carreira
1. Muito Satisfeito

2. Satisfeito

3. Indiferente

4. Insatisfeito

5. Muito Insatisfeito

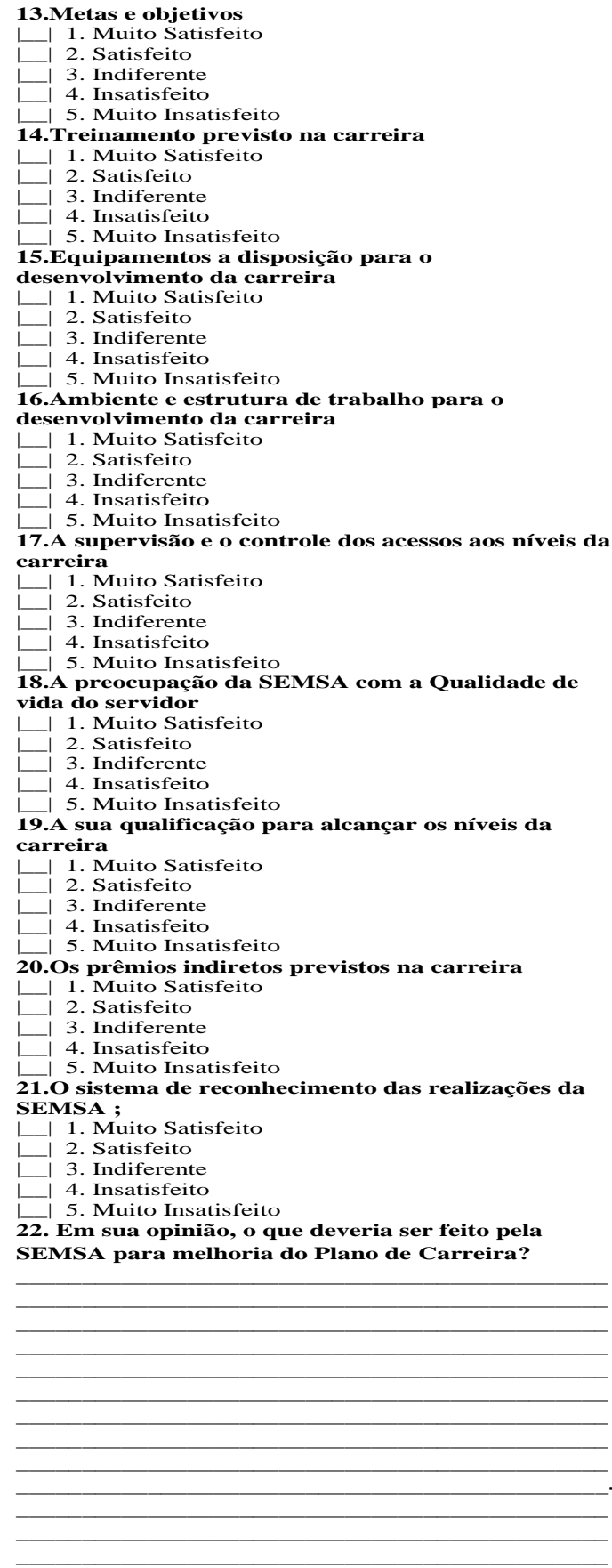

